Note

\section{Synthesis of $(R)$-Enantiomers of 5-Hexadecanolide and 4-Dodecanolide, Pheromone of the Oriental Hornet and a Defensive Secretion of Rove Beetles, Employing Asymmetric Reduction with Immobilized Baker's Yeast}

\section{Yoshinobu Naoshima, Hidenobu Hasegawa and Takaaki SAEKI}

Department of Chemistry, Faculty of Science, Okayama University of Science, Ridai-cho, Okayama 700, Japan

Received July 8, 1987

5-Hexadecanolide (1) is a pheromone component that has been isolated from heads of the queens of the oriental hornet, Vespa orientalis, ${ }^{1}$ and 4-dodecanolide (2) is a defensive secretion isolated from the pygidial glands of rove beetles, Bledius mandibularis and B. spectabilis. ${ }^{2)} \mathrm{A}$ number of methods have recently been reported for the synthesis of enantiomers of the two lactonic compounds, mainly done for either estimating their biological properties or applying a new preparation for obtaining chiral compounds to asymmetric syntheses. ${ }^{3)}$ We had previously synthesized the $(R)$-enantiomers of both lactones $\mathbf{1}$ and $\mathbf{2}$ by combining a two-step alkylation of diethyl 3-oxoglutarate and an asymmetric reduction with free baker's yeast. $^{3 a)}$ The baker's yeast reduction, however, was not satisfactory, leading to the formation of these lactones with low values of specific rotation. We report here a synthesis of the optically pure $(R)$-enantiomers of $\mathbf{1}$ and $\mathbf{2}$, employing an enzymic reduction with the baker's yeast immobilized in $\kappa$-carrageenan beads. ${ }^{4)}$

The monoalkylated 3-oxoglutarates 3 and $\mathbf{6}$ were each easily prepared by initially alkylating diethyl 3-oxoglutarate. For the synthesis of $(R)-\mathbf{1}$, compound 3 was alkylated for the second time by employing 3-iodopropionate, which was followed by a decarboxylative hydrolysis with aqueous sodium hydroxide to give a keto acid 4 in a $71 \%$ yield. The keto acid 4 was converted by an asymmetric reduction with baker's yeast immobilized in carrageenan to an optically pure alcohol 5, which was found to be highly enantiomerically pure, about $100 \%$, by the HPLC analysis of the corresponding MTPA ester $(R)$ $5 \mathbf{a}^{3 \mathrm{~b})}$ Lactonization of $(R)-\mathbf{5}$ gave optically pure $(R)-\mathbf{1}$ in a $75 \%$ yield. Similarly, asymmetric reduction of the keto acid 7 derived from $\mathbf{6}$ and subsequent lactonization gave $(R)$-2. Enantiomers 1 and 2 were fully characterized by comparing their spectral data with those reported. ${ }^{3 a)}$

Although the present reduction system employing immobilized baker's yeast gave lower yields compared with the analogous free baker's yeast system, ${ }^{3 a)}$ this disadvantage will be overcome by reusing the immobilized catalyst.

Determination of the optical purities of $(R)-2$ that was obtained by using both immobilized and free baker's yeast was done by capillary GLC analysis with a chiral stationary phase. The optical purity of the present $(R)-2$ could be estimated to be $100 \%$ e. e., and that of $(R)-2$ previously prepared by the free baker's yeast system ${ }^{3 a)}$ was estimated to be almost $100 \%$ e. e. One $(R)-1$ previously prepared by the free baker's yeast system had showed a lower specific rotation, $[\alpha]_{\mathrm{D}}^{20}+15.8^{\circ}(\mathrm{THF}),{ }^{3 \mathrm{a})}$ compared with the other $(R)-1$ obtained by the present immobilized system. Thus, similar attempts using a chiral stationary phase were made to compare the optical purities of $(R)-\mathbf{1}$ prepared by the two baker's yeast systems, but good results have not yet been obtained.

It is of interest to note that the use of immobilized baker's yeast was of greater advantage than that of free baker's yeast in terms of the separation of the product from the catalyst, reuse of the catalyst, and of the likely optical purity of the product.

\section{EXPERIMENTAL}

IR spectra were obtained on a Hitachi 260-10 spectrometer. ${ }^{1} \mathrm{H}$-and ${ }^{13} \mathrm{C}$ NMR spectra were obtained on Hitachi R-24B and R-90H spectrometers, respectively, in $\mathrm{CDCl}_{3}$ solutions using $\mathrm{Me}_{4} \mathrm{Si}$ as an internal standard. EI and CI mass spectra were recorded on a JEOL JMSD300 mass spectrometer at $70 \mathrm{eV}$ and $200 \mathrm{eV}$ (isobutane), respectively. HPLC was performed on a Gasukuro Kogyo model 576 liquid chromatograph with a UV detector.

Immobilization of baker's yeast with carrageenan. ${ }^{5}$ A mixture of $\kappa$-carrageenan $(6 \mathrm{~g})$ and distilled water $(100 \mathrm{ml})$ was warmed at $60^{\circ} \mathrm{C}$ for $10 \mathrm{~min}$ with stirring. After the resulting clear solution had been cooled to $50^{\circ} \mathrm{C}$, to this was added a mixture of baker's yeast (Oriental Yeast Co., Ltd., Tokyo, $4 \mathrm{~g})$ and distilled water $(20 \mathrm{ml})$, the mixture being stirred for $10 \mathrm{~min}$ until it became homogeneous. A mixture of carrageenan and baker's yeast was added dropwise with a syringe to a $2 \%$ aqueous solution of $\mathrm{KCl}$, and the baker's yeast immobilized in carrageenan beads of ca. $4 \mathrm{~mm}$ diameter was obtained and stored at $5^{\circ} \mathrm{C}$ in an aqueous solution of $\mathrm{KCl}$.

5-Oxohexadecanoic acid, 4. Monoalkylated 3-oxoglutarate $(3,10.4 \mathrm{~g}, 30 \mathrm{mmol})$ was treated with ethyl $3-$ iodopropionate $(6.9 \mathrm{~g}, 30 \mathrm{mmol})$ and then with a $15 \%$ aqueous solution of $\mathrm{NaOH}$ according to procedures described previously. ${ }^{3 a)}$ The mixture was acidified with conc. 


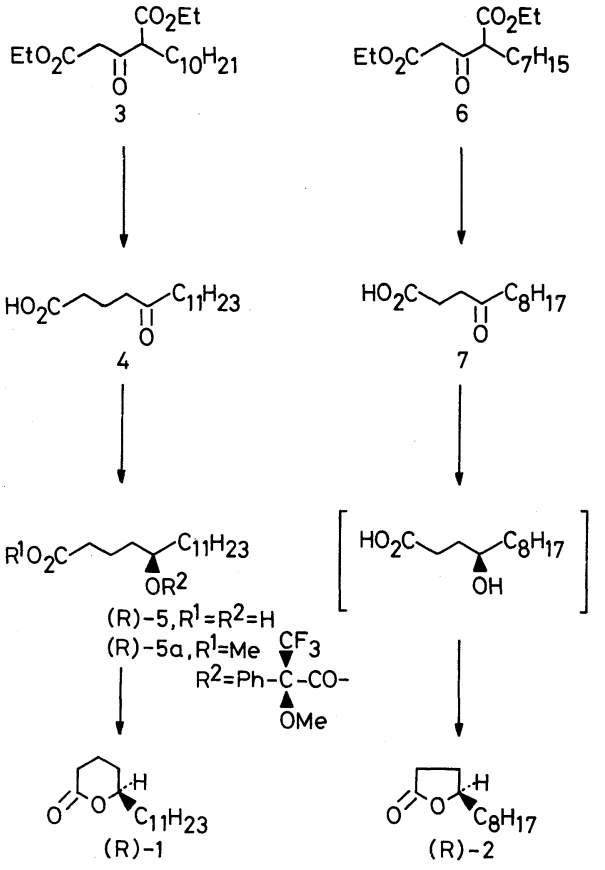

$\mathrm{HCl}$, saturated with $\mathrm{NaCl}$ and extracted with ether. Workup of the ethereal solution gave a yellow solid, which was recrystallized from $n$-hexane to give 4 as needles $(5.83 \mathrm{~g}$, $71 \%$ ) mp $86.5 \sim 87.5^{\circ} \mathrm{C}$. IR $v_{\max }(\mathrm{KBr}) \mathrm{cm}^{-1}: 3200,1700$. ${ }^{1} \mathrm{H}$ NMR $\delta: 0.87(3 \mathrm{H}$, distorted $\mathrm{t}, J=5 \mathrm{~Hz}), 1.15 \sim 2.15$ (20H, br. s at 1.25), $2.26 \sim 2.60(6 \mathrm{H}, \mathrm{m}), 10.50(1 \mathrm{H}$, br. s). ${ }^{13} \mathrm{C}$ NMR $\delta: 210.135(\mathrm{~s}), 178.883$ (s). EIMS $m / z: 270\left(\mathrm{M}^{+}\right.$, 3), $252(\mathrm{M}-18,2), 183$ (25), 130 (90), 112 (100). CIMS $m / z: 271\left[(\mathrm{M}+\mathrm{H})^{+}, 100\right]$. Anal. Found: C, 71.19; H, 11.12. Calcd. for $\mathrm{C}_{16} \mathrm{H}_{30} \mathrm{O}_{3}$ : C, 71.07; $\mathrm{H}, 11.18 \%$.

(R)-5-Hydroxyhexadecanoic acid, $(R)$-5. A mixture of baker's yeast $(40 \mathrm{~g})$ immobilized in carrageenan beads and of D-glucose $(20 \mathrm{~g})$ in a $2 \%$ aqueous solution of $\mathrm{KCl}$ $(1000 \mathrm{ml})$ was incubated at $30^{\circ} \mathrm{C}$ for $6 \mathrm{hr}$ with shaking. To this actively fermenting mixture were added D-glucose $(40 \mathrm{~g})$ and the sodium salt derived from $4(1 \mathrm{~g}, 3.7 \mathrm{mmol})$. The mixture was shaken at $30^{\circ} \mathrm{C}$ for $48 \mathrm{hr}$. The reaction mixture was then filtered, and the filtrate acidified with $6 \mathrm{~N}$ $\mathrm{HCl}$ to $\mathrm{pH} 2 \sim 3$ and extracted with ether. Work-up of the ethereal solution gave crude $(R)-5$, which was purified by column chromatography on silica gel ( $n$-hexane: ethyl acetate $=3: 2$ ) followed by preparative TLC ( $n$ hexane : ethyl acetate $=1: 1)$ to give $(R)-5$ as white solid $(0.32 \mathrm{~g}, 32 \%)$. This was recrystallized from acetone- $n$ hexane, mp $67 \sim 68^{\circ} \mathrm{C}$ (lit. $^{3 \mathrm{~b})} 67 \sim 68^{\circ} \mathrm{C}$ ), $[\alpha]_{\mathrm{D}}^{21.5}-1.15^{\circ}$ $(c=0.25, \mathrm{MeOH})\left[\right.$ lit. $\left.^{3 \mathrm{~b}}[\alpha]_{\mathrm{D}}^{20}-1.07^{\circ}(c=1.03, \mathrm{MeOH})\right]$. The IR and ${ }^{1} \mathrm{H}$ NMR spectra were identical with those reported. ${ }^{3 b)}{ }^{13} \mathrm{C}$ NMR $\delta: 177.725$ (s), 63.723 (d).

(R)-5-Hexadecanolide, $(R)$-1. Compound $(R)-1$ was syn- thesized from $(R)-5(0.2 \mathrm{~g}, 0.74 \mathrm{mmol})$ by the procedure previously described. Column chromatography on silica gel ( $n$-hexane: ethyl acetate $=10: 1$ ) of the product followed by recrystallization from $n$-hexane gave $(R)-1$ $\left(0.14 \mathrm{~g}, 75^{\circ}\right)$ as leaflets, mp $37 \sim 38^{\circ} \mathrm{C}$ (lit. ${ }^{3 \mathrm{~b})} 37^{\circ} \mathrm{C}$ ), $[\alpha]_{\mathrm{D}}^{21.5}+42.4^{\circ} \quad(c=0.14, \quad$ THF $) \quad\left[\right.$ lit. $^{3 \mathrm{~b})} \quad[\alpha]_{\mathrm{D}}^{21.5}+40.2^{\circ}$ $(c=1.76, \mathrm{THF})]$.

4-Oxodecanoic acid, 7. Compound 7 was synthesized from 6 and ethyl bromoacetate according to the procedures described for 4 . Recrystallization of the product from $n$-hexane gave 7 as needles $(4.17 \mathrm{~g}, 65 \%)$, mp $74 \sim 75^{\circ} \mathrm{C}$. IR $v_{\max }(\mathrm{KBr}) \mathrm{cm}^{-1}: 3200,1700 .{ }^{1} \mathrm{H}$ NMR $\delta$ : 0.85 , $(3 \mathrm{H}$, distorted $\mathrm{t}, J=5 \mathrm{~Hz}), 1.12 \sim 1.85(12 \mathrm{H}$, br. $\mathrm{s}$ at 1.28), $2.26 \sim 2.75(6 \mathrm{H}, \mathrm{m}), 11.05$ (1H, br. s). ${ }^{13} \mathrm{C}$ NMR $\delta$ : 208.765 (s), 178.457 (s). EIMS $m / z: 214\left(\mathbf{M}^{+}, 3\right), 196$ $(\mathrm{M}-18,1), 141$ (30), 116 (74), 98 (100). CIMS m/z: 215 $\left[(\mathrm{M}+\mathrm{H})^{+}\right.$, 100]. Anal. Found: C, 67.12; H, 10.29. Calcd. for $\mathrm{C}_{12} \mathrm{H}_{22} \mathrm{O}_{3}: \mathrm{C}, 67.25 ; \mathrm{H}, 10.35 \%$.

(R)-4-Dodecanolide, $(R)-2$. As described for 4, 7 (1 g, $4.7 \mathrm{mmol}$ ) was reduced with immobilized baker's yeast and subsequently lactonized. Column chromatography on silica gel ( $n$-hexane : ethyl acetate $=6: 1)$ of the product followed by preparative TLC ( $n$-hexane:ethyl acetate $=4: 1)$ gave $(R)-2(0.24 \mathrm{~g}, 26 \%$ from 7$),[\alpha]_{\mathrm{D}}^{22.5}+40.34$ $(c=0.22, \mathrm{MeOH})\left[\mathrm{lit}^{3 \mathrm{c})}[\alpha]_{\mathrm{D}}^{20}+41.1^{\circ}(c=5, \mathrm{MeOH})\right]$.

Determination of the optical purity of $(R)-2$. GLC analysis for determining the optical purity of $(R)-2$ was performed on a Hitachi model G-3000 gas chromatograph equipped with a $25 \mathrm{~m} \times 0.25 \mathrm{~mm}$ WCOT fused silica capillary column; stationary phase, Chirasil-L-Val; carrier gas, He $0.47 \mathrm{ml} / \mathrm{min}$; column temperature, $130^{\circ} \mathrm{C}$; split ratio, 1/55. ( \pm$)-2$ was separated into two equal peaks, whose retention times were $25.86 \mathrm{~min}$ and $26.40 \mathrm{~min}$, respectively. When a mixture of $(R)-2$ previously prepared by the free baker's yeast system, the present $(R)-2$ and ( \pm$)-2$ was injected, the peak of longer retention time was clearly enriched. Both the present $(R)-2$ and the previous $(R)-2$ showed a single peak. $(R)-2$ prepared by the two baker's yeast systems was therefore enantiomerically pure.

\section{REFERENCES AND NOTES}

1) R. Ikan, G. Gottlieb and E. D. Bergmann, J. Insect Physiol., 15, 1709 (1969).

2) J. W. Wheeler, G. M. Happ, J. Araujo and J. M. Pasteels, Tetrahedron Lett., 1972, 4635.

3) Synthesis of the enantiomers of $\mathbf{1}$ and $\mathbf{2}$. a) Y. Naoshima, H. Ozawa, H. Kondo and S. Hayashi, Agric. Biol. Chem., 47, 1431 (1983); b) K. Mori and T. Otsuka, Tetrahedron, 41, 547 (1985) and references cited therein.

Synthesis of the enantiomers of 2.

c) G. T. Muys, B. van der Ven and A. P. de Jonge, 
Appl. Microbiol., 11, 389 (1963); d) T. Sugai and K. Mori, Agric. Biol. Chem., 48, 2497 (1984) and references cited therein.

4) More recently, Takeda et al. have reported the preparation of enantiomerically pure 3-hydroxy esters by using baker's yeast immobilized in calcium alginate gels. ${ }^{6}$
5) T. Tosa, T. Sato, T. Mori, K. Yamamoto, I. Takata, Y. Nishida and I. Chibata, Biotechnol. Bioeng., 21, 1697 (1979).

6) T. Sakai, T. Nakamura, K. Fukuda, E. Amano, M. Utaka and A. Takeda, Bull. Chem. Soc. Jpn., 59, 3185 (1986). 